\section{Agglutination Reactions in Human Red Cells Fragmented by Heat}

Murray and Clark ${ }^{1}$ have shown that, if red cells are heated to $50^{\circ} \mathrm{C}$., substances can be obtained from the surrounding fluid which, even if derived from $R h$-negative red cells, can give rise to anti- $D$ agglutinins when injected into guinea pigs. Temperatures in the neighbourhood of $50^{\circ}-56^{\circ}$ produce extensive modifications of the human red-cell surface, namely, fragmentation, development of myelin forms, and, at the higher temperatures, hæmolysis ${ }^{2}$. It is therefore likely that the substances found by Murray and Clark in the fluid surrounding the heated cells are the products of the fragmentation phenomena and the changes in the red-cell surface which accompany them.

Thrice-washed human red cells (group $O, C D E$ positive) are heated for $10 \mathrm{~min}$. at $50^{\circ}, 52^{\circ}, 54^{\circ}$ and $56^{\circ} \mathrm{C}$., and then tested for their reactivity with anti- $D$ serum at $37^{\circ} \mathrm{C}$. As the temperature is increased, the fragmentation and hæmolytic phenomena become more and more pronounced, as already described ${ }^{2}$, and as can be seen by examining the suspensions by phase contrast. At the same time, the serological reactivity of the red cell surface becomes modified. Agglutination by 'complete' (saline agglutinin) antibody becomes progressively weaker as the temperature to which the cells are heated is increased, and is almost lost after heating to $56^{\circ} \mathrm{C}$. However, cells which have been heated even to $56^{\circ} \mathrm{C}$. will react with 'incomplete' (blocking) antibody, as shown by a positive indirect Coombs reaction. The cell surface is not modified to such an extent, however, as to give a positive direct Coombs reaction.

Similar experiments show that heating progressively decreases the trypsinizability of red cells, and progressively decreases the reactivity of red cells which have been trypsinized before the heating.

The material obtained by ultracentrifuging the - heated preparations, that is, the material which Murray and Clark find to be antigenic in the guinea pig, consists of tiny fragments and myelin forms. The reactivity of their surfaces, however, is so reduced that no agglutination-like phenomena can be produced by the addition of anti- $D$ sera.

\section{RUTH PONDER}

Nassau Hospital,

Mineola, N.Y. Aug. 5.

${ }^{1}$ Murray, J. M., and Clark, E. C., Nature, 169, 887 (1952).

${ }^{2}$ Ponder, E., J. Exp. Biol., 26, 35 (1949); 27, 198 (1950).

\section{Pseudo-Cholinesterase of Brain}

ShortLy after the distinction had been made between the true cholinesterase and the pseudocholinesterase ${ }^{1,2}$, it was claimed that the brains of vertebrates contain true cholinesterase only ${ }^{3}$. This latter statement has proved to be incorrect; when large amounts of tissue are used for cholinesterase determinations, the presence of a small amount of pseudo-cholinesterase in brain can be demonstrated ${ }^{4,5}$. Experiments with selective inhibitors of pseudocholinesterase have rendered it highly improbable that this enzyme would have any important role in the hydrolysis of acetylcholine released at nerve endings ${ }^{6-8}$. However, the pseudo-cholinesterase in brain appears to be associated particularly with the myelinated fibre tracts of the central nervous system, and it has been suggested that the activity of this esterase may be connected with processes occurring in the myelin sheaths or neuroglial elements of the nervous system ${ }^{5}$.

This suggestion is especially interesting in view of the fact that tri-ortho-cresyl phosphate (TOCP), which is known to be a selective inhibitor of pseudocholinesterase", causes paralysis in many species with demyelination of the peripheral nerves, degenerative changes in the anterior horn cells, and fatty degeneration in the white matter of the spinal cord ${ }^{9}$. Studies on the inhibition of the cholinesterases by tri-orthocresyl phosphate in vitro have been carried out recently by Earl and Thompson ${ }^{10}$, who suggested that inhibition of the pseudo-cholinesterase by this substance might play a part in the demyelination and consequent paralysis. We have also investigated the significance of the pseudo-cholinesterase in brain along two lines in our laboratory.

First, a very detailed study on the cholinesterase activity of ox brain failed to reveal the presence of any pseudo-cholinesterase, thus confirming a previous report ${ }^{11}$ on the absence of pseudo-cholinesterase in various other tissues of this species and of the sheep. The absence of pseudo-cholinesterase from the tissues of ruminants shows that the paralysis due to triortho-cresyl phosphate, which can also be produced in ruminants ${ }^{9,12,13}$, is not likely to be due to inhibition of pseudo-cholinesterase.

Nevertheless, we thought it necessary to substantiate this conclusion by inhibiting the pseudocholinesterase in a species the brain of which does contain this enzyme. Three groups of young male rats of a crossed Wistar-piebald strain, weighing between 75 and 85 gm., were used in this experiment. One group served as controls, the second group was injected subcutaneously with $0.5 \mathrm{ml}$. tri-ortho-cresyl phosphate, while the third group was injected intramuscularly with $0.05 \mathrm{ml}$, and after six weeks with $0.1 \mathrm{ml}$. of this substance. The injections were repeated every four days for three weeks, and from then on once a week for a total period of fourteen weeks. Animals were sacrificed at various times to determine the cholinesterase activities of the tissues by the methods described by Mendel et al. ${ }^{2}$ and Thompson et $a l .{ }^{5,10}$. The cholinesterase activities of the tissue homogenates were determined manometrically with $0.03 M$ acetyl- $\beta$-methylcholine ${ }^{2}$ as specific substrate for the true cholinesterase, and $0.006 \mathrm{M}$ benzoylcholine ${ }^{2}$ and $0.03 \mathrm{M}$ butyrylcholine $^{5,10}$ as specific substrates for the pseudocholinesterase. Esterase activities are expressed as $\mu l$. carbon dioxide produced per $\mathrm{hr}$. per $100 \mathrm{mgm}$. tissue or per ml. serum (see table). The rats of group II were injected subcutaneously with $0.5 \mathrm{ml}$. tri-ortho-cresyl phosphate and those of group III intramuscularly with $0.1 \mathrm{ml}$. In both groups of rats treated with tri-ortho-cresyl phosphate, the pseudo-cholinesterase of brain was almost completely inhibited from the seventh day until the end of the experiment.

During this period of fourteen weeks, each of the seven remaining rats of the second group gained about $160 \mathrm{gm}$. on the average, those of the third group $300 \mathrm{gm}$. and the control animals $320 \mathrm{gm}$. Despite the complete and prolonged inhibition of the pseudocholinesterase in brain, none of the animals showed any signs of paralysis. The rats of the third group were indistinguishable in appearance from the controls; histological examination of the brain, spinal cord and sciatic nerves of these animals did not reveal any demyelination or other abnormalities. 